\title{
Hubungan Lama Pemakaian Diaper dengan Kejadian Diaper Rash pada Bayi Usia 9-12 Bulan
}

\section{The Relationship Between Diaper Usage Duration and Diaper Rash in Infants Aged 9-12 Months}

\author{
Dwi Ertiana $^{1 *}$, Febriani Dyah Antika Sari ${ }^{2}$ \\ 1. Prodi DIV Bidan Pendidik STIKES Karya Husada Kediri, Indonesia \\ 2. Prodi DIV Bidan Pendidik STIKES Karya Husada Kediri, Indonesia \\ *Email korespondensi: ertiana.dwi@gmail.com
}

\begin{abstract}
Abstrak
Latar belakang: Bayi mengalami beberapa gangguan salah satunya diaper rash. Agar bayi tidak mengalami hal tersebut maka perlu diperhatikan penggunaan diaper pada bayi. Diaper sekali pakai atau diaper modern telah menyebabkan peningkatan kesehatan kulit dengan penurunan frekuensi dan keparahan diaper rash.

Tujuan: Mengetahui hubungan lama pemakaian diaper dengan kejadian diaper rash pada bayi usia 912 bulan.

Metode: Jenis penelitian adalah observasional dengan pendekatan cross sectional dan menggunakan teknik simple random sampling. Responden adalah bayi berusia 9-12 bulan di Posyandu Canggu Badas Kediri pada tanggal 17 April sampai 15 Mei 2018 sebanyak sebanyak 47 responden. pengambilan data menggunakan lembar observasi dan lembar ceklist. Data dianalisis menggunakan uji spearman rank.

Hasil: Sebanyak 24 responden $(51,1 \%)$ mengalami diaper rash dan 15 responden $(31,9 \%)$ tidak mengalami diaper rash, nilai korelasi spearman sebesar 0,512 dengan p-value sebesar 0,023 $(<0,05)$. Responden mengalami diaper rash disebabkan lama pemakaian diaper lebih dari tiga jam dengan frekuensi BAK paling banyak 6-8 kali sehari.

Kesimpulan: Terdapat hubungan antara lama pemakaian diaper dengan kejadian diaper rash pada bayi usia 9-12 bulan. Responden hendaknya melakukan pergantian popok pada bayinya paling tidak 3 jam sekali agar tidak terjadi diaper rash.
\end{abstract}

Kata kunci: Bayi; Diaper Rash; Lama Pemakaian Diaper

\begin{abstract}
Background: One of infant disorders experienced is diaper rash. It is necessary to pay attention to use diapers so that infants do not experience diaper rash. Disposable diapers or modern diapers has led to improved skin health with a decrease in the frequency and severity of diaper rash.

Objective: Relationship between diaper usage duration with the incidence of diaper rash in infants aged 9-12 months.

Method: This observational research with a cross sectional and using simple random sampling technique. The sample were infants aged 9-12 months at Posyandu in Canggu Village, Badas Subdistrict, Kediri Regency on April 17 to May 15 2018, with 47 respondents. Data collection techniques using observation and form checklist. Data analysis uses Spearman rank test.

Result: The results 24 respondents $(51,1 \%)$ had diaper rash and 15 respondents $(31,9 \%)$ did not experience diaper rash, the Spearman correlation value was 0.512 with a p-value $0.023(<0.05)$. Respondents experienced a diaper rash due to the duration of using diapers for more than three hours with the frequency of urinating at most 6-8 times a day.

Conclusion: There is a relationship between the duration of diaper use and the incidence of diaper rash in infants aged 9-12 months. Respondents should have diaper changed for their baby at least every 3 hours to prevent diaper rash.
\end{abstract}

Keywords: Baby; Diaper Rash; Length of use of Diaper 


\section{PENDAHULUAN}

Kebersihan merupakan hal sangat penting yang harus diterapkan dalam kehidupan sehari-hari, terutama apabila mempunyai bayi maka kita juga harus ekstra dalam melindungi bayi kita, karena bayi mempunyai kulit yang sangat sensitif. Sosial budaya merupakan hal yang mempengaruhi kebersihan dalam kehidupan sehari-hari. Kesehatan bayi sangat dipengaruhi oleh kebersihan. Penggunaan diaper pada bayi merupakan hal yang sangat efektif yang bisa digunakan untuk menjaga kebersihan pada kulit bayi terutama didaerah genetalia. Diaper dapat digunakan untuk menampung air kencing dan kotoran bayi. Kulit bayi sangat sensitif sehingga apabila penggunaan popok sekali pakai terlalu lama dapat menyebabkan gangguan pada kulit bayi (1).

Perlu diperhatikan dengan baik penggunaan diaper untuk bayi. Diaper memainkan peran penting dalam kebersihan bayi, dan daya serap yang lebih besar dari diaper sekali pakai atau diapers modern telah menyebabkan peningkatan kesehatan kulit dengan penurunan frekuensi dan keparahan diaper rash (2). Salah satu bagian tubuh yang dapat melindungi dari dunia luar yaitu kulit. Namun kulit juga memiliki keterbatasan dalam melindungi tubuh karena adanya zat-zat tertentu yang dapat merusaknya. Banyak bayi yang mengalami diaper rash dibeberapa titik sehingga apabila cukup parah dapat mempengaruhi sifat pelindung dari kulit itu sendiri dan menyebabkan ketidaknyamanan pada bayi (3).

Penggunaan bahan-bahan pada popok sudah terpilih untuk menjaga keamanan terhadap kulit bayi. Diaper rash tidak terjadi pada semua kulit namun pada sebagian kecil dari kulit yang terkena, sedangkan tingkat keparahan dari kulit biasanya ringan sehingga kulit tetap dapat berfungsi untuk melindungi bayi. Diaper rash dapat mengubah untuk masukanya bahan kimia ke kulit. Tidak semua bahan kimia dapat mempengaruhi kulit, namun keamanan pada kulit bayi tetap harus diutamakan agar bayi tidak mengalami diaper rash (4).

Diaper yang merupakan alat untuk menampung kotoran dan air kencing bayi yang berbahan plastik dan beberapa zat kimia tertentu mempunyai kemampuan sangat baik dalam menjaga kulit bayi agar tetap kering, sehingga penggunaanya juga perlu diatur karena akan menyebabkan diaper rash pada bayi (5).

Masyarakat sekarang ini mempunyai kemudahan karena banyak hal yang dibuat dengan sangat bagus dan maju yang dapat memudahkan masyarakat. Dahulu perlu mengganti dan mencuci beberapa kali pada saat popok basah, namun saat ini sudah tersedia beberapa merk popok sekali pakai atau diapers yang dapat digunakan untuk bayi terutama pada ibu yang bekerja akan lebih mudah pada saat mengantinya. Banyaknya diapers yang beredar dipasaran juga perlu diperhatikan karena kulit bayi sangat sensitif apabila diaper yang digunakan tidak nyaman pada saat dipakai, karena apabila tidak diperhatikan dapat menyebakan gangguan pada kulit bayi. Beberapa masalah yang sering terjadi pada kulit bayi adalah miliaria, iritasi, diaper rash (5).

Sebanyak $50 \%$ bayi yang memakai diaper akan mengalami iritasi pada kulit ditandai dengan adanya kemerahan, menggelembung yang biasanya terjadi pada bokong, lipatan paha dan area genetalia, serta bayi menjadi rewel. Hal ini biasanya dialami pada bayi 7-35 \% dari populasi bayi di Indonesia (5).

Berdasarkan penelitian sebelumnya tentang lamanya penggunaan diaper didapatkan hasil bahwa penggunaan diaper yang terlalu lama akan menyebabkan perkembangan bakteri mikro yang semakin meningkat sehingga dapat menyebabkan terjadinya diaper rash dengan nilai $p$ value 0,004. Penelitian tersebut menyebutkan bahwa 66,67 \% mengalami diaper rash dan $33,33 \%$ yang tidak mengalami diaper rash (6). Gangguan pada kulit bayi akan terjadi apabila kulit kontak dengan lingkungan yang tidak baik secara terus menerus, contohnya penggunaan diaper yang tidak baik. Gangguan tersebut terjadi pada kulit yang tertutup terutama pada 
daerah genetalia pada tubuh bayi. Hal ini karena kulit akan terasa lembab sehingga akan terjadi gangguan pada kulit (7).

Sekitar 50\% bayi pernah mengalami diaper rash yang merupakan gangguan sering terjadi pada bayi. Prevalensi tertinggi didapatkan pada bayi berusia 9-12 bulan. Kejadian tersebut terjadi mulai dari 7,1 \% sampai $61 \%$. kejadian diapers rash pada bayi di Inggris terjadi sekitar $25 \%$. Sebayak 54\% bayi berumur 1 bulan yang mengalami diaper rash setelah memakai popok(5). Penelitian lain juga mendapatkan hal yang sama bahwa kejadian diaper rash terjadi sekitar $15 \%$ sampai 50\%(8).

Dari 17 responden yang memakai diaper didapatkan 15 bayi mengalami diaper rash karena sering menggunakan diaper, hanya 2 responden yang tidak mengalami diaper rash. Hal tersebut bisa disebabkan karena kulit bayi tersebut tidak terlalu sensitif sehingga meskipun menggunakan diaper tidak mengalami gangguan dan karena diaper yang digunakan memiliki tipe yang baik atau lebih lembut (5).

Diaper dibuat dengan bahan yang dapat menjaga atau membantu kulit bayi tetap kering. Namun diaper tidak langsung diganti ketika setiap kali bayi buang air kecil sehingga dapat menyebabkan hidrasi pada kulit yang langsung bersentuhan dengan diaper dibandingkan dengan bayi yang tidak menggunakan diaper. Apabila penggunaan diaper tetap dijaga kebersihannya dengan periode pemakaian yaitu 4 jam saat siang serta 8 jam saat malam hari maka akan mengurang implikasi dari diaper. Hal tersebut dapat memperbaiki sirkulasi kulit yang menggunakan diaper (9).

Diaper rash merupakan kelainan kulit yang biasanya menyerang bayi. Dalam kebanyakan masalah, diaper rash terjadi pada daerah terbatas yaitu pada genital dan perinal dan tidak melibatkan semua atau bahkan sebagian besar kulit, hanya sebatas kulit bayi yang terkena diaper. Faktor penyebab terjadinya diaper rash yaitu faktor fisik, kimiawi, enzimatik dan mikroba yang umumnya tidak berhubungan dengan diaper sendiri apabila diaper kotor tidak segera diganti, maka akan ada garam empedu dan zat pengiritasi lainnya dalam tinja dapat mengurai lipid pelindung dan protein di stratum korneum (10). Campuran urine dan feses dapat meningkatkan $\mathrm{pH}$ kulit yang dapat mengaktifkan enzim feses yang selanjutnya dapat berkontribusi pada iritasi kulit. Gesekan dan abrasi mekanis, terutama jika kulit kotor, juga dapat menyebabkan iritasi. Selain itu, jika diaper tidak sering diganti dalam waktu lama dapat menyebabkan kulit terhidrasi berlebihan yang membuatnya lebih rentan (11)(12).

Penyebab utama diaper rash gesekan dan kontak kulit yang lama dengan urin, feses, salep yang dapat menyebabkan kulit yang erimatosal dan bersisik disertai lesi papulo vesikular atau lesi bulosa, fisura, atau erosi. Infeksi sekunder yang diakibatkan bakteri sering ditemukan. Peradangan dapat menimbulkan ketidaknyamanan berat. Diaper sekali pakai, flu, atau saat bertumbuhan gigi juga bisa menyebabkan diaper rash (6). Diaper rash terjadi 2-3 hari, namun kejadian ini bervariasi pada setiap bayi yang mengalaminya karena tergantung pada tingkat keparahan dari kejadian diaper rash itu sendiri dan banyak atau tidaknya kulit yang mengalami diaper rash (13)(14).

Guna menghindari diaper rash sebaiknya kulit harus selalu dijaga agar selalu kering dan mengurangi kontak yang terlalu lama dengan hasil metabolisme tubuh yaitu air kencing dan kotoran bayi, kulit dibersihkan dengan air, penggunaan bedak juga harus dihindari. Untuk mengurangi terjadinnya diapers rash maka harus sering mengganti diaper yang digunakan pada bayi, sering mengecek diaper sudah penuh atau belum, menggunakan diaper yang tidak terlalu ketat agar kulit bayi tetap mendapatkan sirkulasi dan genetalia bayi tidak lembab, kurangi penggunaan diaper yang terlalu sering, pada saat membersikan sisa kotoran hasil metabolisme pada bayi terutama air kencing dan feses bayi maka jangan sampai ada sisa kotoran tersebut. Apabila tidak bersih saat membersihkannya maka akan menyebabkan bayi mengalami diaper rash (15) (16). 
Menurut Bidan Desa Canggu Kecamatan Badas Kabupaten Kediri, banyak ibu yang memiliki bayi datang dengan keluhan bayi mengalami kulit kemerahan dan bintik-bintik merah pada bagian pantat bayi, sehingga menyebabkan bayi rewel, terdapat 182 bayi usia 012 bulan, sedangkan bayi usia 9-12 bulan sejumlah 53 bayi.

Diaper rash dapat mengakibatkan gangguan pada pelindung kulit bayi. Penggunaan diaper yang lama dapat menyebabkan diaper rash yang mengganggu kesehatan dari kulit bayi. Selain kurang terjaganya kebersihan dari bayi dari lingkungan juga karena kurangnya pengetahuan orang tua mengenai diaper rash. Disamping itu juga dapat mengganggu pertumbuhan dan perkembangan bayi, karena hal tersebut bayi dapat mengalami gangguan untuk susah tidur dan rewel(17).

Guna memahami dampak dari diaper rash pada potensi peningkatan penetrasi kulit dari zat yang bersentuhan dengan kulit, seseorang perlu memiliki informasi tentang frekuensi, tingkat keparahan, jumlah kulit yang terlibat, dan durasi diaper rash. Perkembangan diaper rash sangat dipengaruhi oleh kebiasaan dan praktik pengasuh sehingga prevalensinya sangat bervariasi di berbagai wilayah di dunia. Ada beberapa perkembangan yang mengikuti perkembangan dan resolusi insiden diaper rash dari waktu ke waktu, sehingga informasi statistik tentang diaper rash biasanya hanya memberikan informasi tentang dalam waktu tertentu (3).

Pada kasus ruam yang lebih parah melibatkan area kulit lebih luas, pengunaan bahan medis sering digunakan untuk mengatasi diaper rash misalnya menggunakan krim yang sering dioleskan ke kulit, yang akan mengurangi dampak dari diaper rash (18). Sebagian besar diaper rash merupakan kasus sederhana dari dermatitis kontak iritan (misalnya, dari seringnya kontak dengan urin dan feses) yang responsif terhadap pengobatan topikal dan pendidikan orang tua tentang praktik penggunaan popok yang benar. Pada saat kebersihan baik dan seringnya mengganti diaper akan mengurangi kemungkinan berkembangnya diaper rash, hal itu dapat terjadi ketika praktik penggunaan diaper yang baik dilaksanakan (10).

Lama pemakaian diaper digunakan maksimal tiga jam sesuai dengan dengan waktu pada saat bayi minum. Diaper hendaknya diganti sekitar 3 jam sekali, agar kulit bayi tidak terlalu lama bersentuhan dengan asam laktat yang dapat menyebabkan gangguan pada kulit bayi. Seringnya mengganti diaper maka akan membuat bayi terasa nyaman dan menghindari dari terjadinya diapers rash. Orang tua juga bisa memilih diaper yang memiliki bahan yang lembut dan baik untuk kulit bayi.

Akibat kurangnya pemahaman atau pengetahuan ibu tentang pemakaian diaper maka peneliti ingin melakukan penelitian dengan judul "Hubungan lama pemakaian diaper dengan kejadian diaper rash pada bayi usia 9-12 bulan di Posyandu Desa Canggu Kecamatan Badas Kabupaten Kediri.

\section{METODE}

Penelitian ini merupakan penelitian observasional atau mengobservasi diaper rash menggunakan pendekatan cross sectional. Penelitian dilaksanakan tanggal 17 April sampai 15 Mei 2018 di Poyandu Desa Canggu Kecamatan Badas Kabupaten Kediri. Populasi pada penelitian ini yaitu bayi berusia 9 - 12 bulan sebanyak 53 orang, responden adalah bagian dari populasi sebanyak 47 orang yang diperoleh dengan teknik simple random sampling. Data dikumpulkan menggunakan lembar observasi dan lembar ceklist. Analisa data menggunakan uji spearman rank untuk menganalisis hasil observasi terhadap responden. Hipotesis penelitian adalah terdapat hubungan lama pemakaian diaper dengan kejadian diaper rash pada bayi usia 9-12 bulan di Posyandu Desa Canggu Kecamatan Badas Kabupaten Kediri. Penelitian ini telah lulus kaji etik di STIKES Karya Husada Kediri dengan nomor surat keterangan kelaikan etik yaitu 680.E/EC/LPPM/STIKES/KH/IV/2018. Pada saat 
pengumpulan data, responden diberikan terlebih dahulu informed consent (persetujuan untuk ikut serta dalam penelitian), dan semua responden setuju untuk ikut dalam penelitian.

HASIL

1. Data Univariat

Tabel 1. Karakteristik Responden di Posyandu Desa Canggu Kecamatan Badas Kabupaten Kediri Tanggal 17 April sampai 15 Mei Tahun 2018.

\begin{tabular}{cccc}
\hline \multirow{2}{*}{ No } & Karakteristik & \multicolumn{2}{c}{ Total } \\
\cline { 3 - 4 } & Responden & Jumlah (n) & Persentase (\%) \\
\hline 1 & Usia & 29 & 61,70 \\
& $9-10$ bulan & 18 & 38,30 \\
\hline 2 & Konsumsi Susu & & \\
& ASI & 24 & 51,06 \\
& Susu Formula & 23 & 48,94 \\
\hline 3 & Frekuensi BAK & & \\
& <6 kali & 7 & 14,89 \\
& 6-8 Kali & 31 & 65,96 \\
& 8> kali & 9 & 19,15 \\
\hline 4 & Penggunaan Bedak & & \\
& Salycil & & 3,17 \\
& Selalu diberi & 17 & 29,79 \\
& Jarang diberi & 14 & 34,04 \\
& Tidak pernah & 16 & \\
& diberi & & 82,98 \\
\hline 5 & Jenis Diaper & & 17,02 \\
\hline & Diaper disposable & 39 &
\end{tabular}

Tabel 1 menunjukkan bahwa sebagian besar responden berusia 9-10 bulan yaitu sebanyak 29 responden $(61,70 \%)$. Hampir setengahnya responden mengkonsumsi ASI yaitu sejumlah 23 responden $(48,94 \%)$. Responden mengalami frekuensi BAK 6-8 kali yaitu sejumlah 31 responden $(65,96 \%)$. Hampir setengahnya responden selalu menggunakan bedak salycil yaitu sejumlah 17 responden (36,17\%). Responden menggunakan jenis diaper disposable yaitu sejumlah 39 responden $(82,98 \%)$.

\section{Data Bivariat}

Tabel 2. Hasil Tabulasi Silang Antara Lama Pemakaian Diaper dengan Kejadian Diaper Rash di Posyandu Desa Canggu Kecamatan Badas Kabupaten Kediri Tanggal 17 April sampai 15 Mei Tahun 2018

\begin{tabular}{|c|c|c|c|c|c|c|c|c|}
\hline \multirow{3}{*}{ Lama Pemakaian Diaper } & \multicolumn{6}{|c|}{ Kejadian Diaper Rash } & \multirow{2}{*}{\multicolumn{2}{|c|}{ Total }} \\
\hline & \multicolumn{2}{|c|}{ Sedang } & \multicolumn{2}{|c|}{ Ringan } & \multicolumn{2}{|c|}{$\begin{array}{c}\text { Tidak Diaper } \\
\text { Rash }\end{array}$} & & \\
\hline & $\mathrm{n}$ & $\%$ & $\mathrm{n}$ & $\%$ & $\mathrm{n}$ & $\%$ & $\mathrm{n}$ & $\%$ \\
\hline$\leq 3$ jam (Efektif) & 0 & 0 & 8 & 17 & 15 & 31,9 & 23 & 48,9 \\
\hline > 3 jam (Tidak efektif) & 16 & 34 & 8 & 17 & 0 & 0 & 24 & 51,1 \\
\hline Total & 16 & 34 & 16 & 34 & 15 & 31,9 & 47 & 100 \\
\hline
\end{tabular}


Berdasarkan tabel 3 sebanyak 34,0\% responden mengalami diaper rash dengan lama pemakaian diaper tidak efektif. Hasil uji Spearman rank correlation didapatkan nilai korelasi Spearman sebesar 0,512 dengan p-value sebesar 0,023 $(<0,05)$ sehingga $\mathrm{H}_{1}$ diterima dan dapat disimpulkan bahwa ada hubungan lama pemakaian diaper dengan kejadian diaper rash pada bayi usia 9-12 bulan.

\section{PEMBAHASAN}

Hasil penelitian menunjukkan bahwa dari total sampel 47 responden didapatkan lama pemakaian diaper sebagian besar lebih dari 3 jam yaitu ada sejumlah 24 responden $(51,1 \%)$ dan lama pemakaian diaper hampir setengahnya kurang dari sama dengan 3 jam yaitu sejumlah 23 responden (48,9\%). Berdasarkan data yang di dapatkan dari tabel frekuensi BAK bayi yang paling banyak yang mengalami BAK frekuensi 6-8 kali yaitu sebagian besar sebanyak 16 bayi $(69,0 \%)$ dalam lama pemakaian kurang dari sama dengan 3 jam.

Masyarakat sekarang ini mempunyai kemudahan karena banyak hal yang dibuat dengan sangat bagus dan maju yang dapat memudahkan masyarakat. Dahulu perlu mengganti dan mencuci beberapa kali pada saat popok basah, namun saat ini sudah tersedia beberapa merk popok sekali pakai atau diapers yang dapat digunakan untuk bayi terutama pada ibu yang bekerja akan lebih mudah pada saat mengantinya. Banyaknya diapers yang beredar dipasaran juga perlu diperhatikan karena kulit bayi sangat sensitif apabila diaper yang digunakan tidak nyaman pada saat dipakai, karena apabila tidak diperhatikan dapat menyebakan gangguan pada kulit bayi. Beberapa masalah yang sering terjadi pada kulit bayi adalah miliaria, iritasi, diaper rash (5).

Sebanyak $50 \%$ bayi yang memakai diaper akan mengalami iritasi pada kulitnya ditandai dengan adanya kemerahan, menggelembung yang biasanya terjadi pada bokong, lipatan paha dan area genetalia, serta bayi biasanya menjadi rewel. Hal ini biasanya dialami pada bayi 7-35 $\%$ dari populasi bayi di Indonesia (19).

Lama pemakaian diaper yang tidak efektif dapat menyebabkan terjadinya diaper rash pada bayi. Semakin lama penggunaan diaper (tidak efektif) maka semakin berat pula kejadian diaper rash pada bayi. Di Posyandu Desa Canggu Kecamatan Badas Kabupaten Kediri sebagian besar lama penggunaan diaper lebih dari 3 jam secara tidak efektif, dan hampir setengahnya kurang dari sama dengan 3 jam secara efektif. Oleh karena itu seorang ibu butuh ketelatenan untuk dapat memperhatikan lama pemakaian atau penggunaan diaper pada bayinya. Memperhatikan lama pemakaian diaper tersebut dapat dilakukan ibu dengan setiap tiga jam melihat bagaimana keadaan diaper yang digunakan bayinya dan segera menggantinya bila sudah waktunya tiga jam dan atau jika keadaan diaper sudah waktunya untuk diganti, misalnya jika diaper yang digunakan jenis pampers sudah penuh atau jika jenis kain diaper basah atau terkena kotoran bayi.

Hasil penelitian menunjukkan bahwa dari total sampel 47 responden didapatkan hampir setengahnya pada kategori ringan dan sedang yaitu kategori ringan sejumlah 16 responden $(34,0 \%)$ dan kategori sedang sejumlah 16 responden $(34,0 \%)$, dilihat dari tabel penggunaan jenis popok bahwa banyak ibu yang menggunakan diaper disposable yaitu hampir setangahnya 16 responden $(41,0 \%)$.

Diaper rash terjadi karena lingkungan yang tidak baik, hal tersebut bisa disebabkan karena kulit kontak terlalu lama dengan air kecing atau kotoran bayi. Selain itu juga bisa disebabkan karena penggunaan diaper yang terlalu ketat dan tidak benar serta bisa dikarenakan diaper yang digunakan terlalu kasar sehingga dapat menyebabkan kulit bayi mengalami iritasi, dengan ditandai dengan ada warna kemerahan pada kulit bayi, adanya gelembung yang berwarna merah, lecet atau luka yang terdapat sisiknya. Biasanya bayi 
mengalami tidak nyaman dan sering menangis dan rewel. Diaper rash sering terjadi pada daerah genetalia atau sekitarnya yang tertutup oleh diaper (7).

Berdasarkan penelitian sebelumnya tentang lamanya penggunaan diapers didapatkan hasil bahwa penggunaan diaper yang terlalu lama akan menyebabkan perkembangan bakteri mikro yang semakin meningkat sehingga dapat menyebabkan terjadinya diapers rash dengan nilai $p$ value 0,004. Dari penelitian tersebut didapatkan hasil bahwa 66,67 \% mengalami diaper rash dan 33,33\% yangtidak mengalami diaper rash (6).

Penyebab utama diaper rash gesekan dan kontak kulit yang lama dengan urin, feses, salep yang dapat menyebabkan kulit yang erimatosal dan bersisik disertai lesi papulo vesikular atau lesi bulosa, fisura, atau erosi. Infeksi sekunder yang diakibatkan bakteri sering ditemukan. Peradangan dapat menimbulkan ketidaknyamanan berat. Diaper sekali pakai, flu, atau saat bertumbuhan gigi juga bisa menyebabkan diaper rash (6). Diaper rash terjadi 2-3 hari, namun kejadian ini bervariasi pada setiap bayi yang mengalaminya karena tergantung pada tingkat keparahan dari kejadian diaper rash itu sendiri dan banyak atau tidaknya kulit yang mengalami diaper rash (13) (14).

Terjadinya diaper rash pada responden sebagian besar dikarenakan lama pemakaian diaper yang tidak efektif yaitu lebih dari 3 jam. Semakin lama pemakaian diaper yang tidak efektif maka semakin berat juga kejadian diaper rash pada bayi. Terjadinya diaper rash juga dapat disebabkan karena kulit bayi yang sensitif oleh plastik atau karet dari diaper yang digunakan, dan juga karena kurangnya kebersihan kulit bayi. Pada penelitian ini ditemukan paling banyak adalah bayi yang menggunakan diaper disposable yaitu popok yang digunakan sekali pakai dan kejadian diaper rash paling banyak ditemukan pada bayi yang menggunakan diaper disposable. Hal ini membuktikan juga bahwa penggunaan diaper disposable lebih dominan menimbulkan diaper rash dibandingkan dengan diaper kain, karena ketidaktauan ibu untuk selalu mengganti diaper tiap 3 jam sekali.

Dari hasil uji Spearman rank sebesar 0,512 dengan p-value yaitu 0,023 $(<0,05)$ sehingga $\mathrm{H}_{1}$ diterima yang berarti terdapat hubungan lama pemakaian diaper dengan kejadian diaper rash pada bayi usia 9-12 bulan di Posyandu Desa Canggu Kecamatan Badas Kabupaten Kediri. Berdasarkan tabel 6 diatas diketahui bahwa bayi yang mengalami diaper rash mayoritas atau paling banyak lama pemakaian diapernya tidak efektif yaitu lebih dari 3 jam, dan bayi yang tidak mengalami diaper rash, lama pemakaiannya secara efektif yaitu kurang dari sama dengan 3 jam. Dilihat dari keseluruhan mayoritas lama pemakaian diaper tidak efektif yaitu sebesar 24 responden $(51,1 \%)$.

Keadaan diatas menunjukkan bahwa lama pemakaian diaper yang tidak efektif dapat mengakibatkan terjadinya diaper rash, penyebab diaper rash yang lain yaitu terlalu lamanya kulit bersentuhan dengan air kencing dan feces bayi sehingga menyebabkan bayi mengalami hal tersebut, serta penggunaan diaper yang terlalu ketat sehingga menyebabkan area genetalia bayi menjadi lembab. Hal terebut yang merupakan salah satu penyebab terjadianya diaper rash.

Sekitar 50\% bayi pernah mengalami diaper rash yang merupakan gangguan yang sering terjadi pada bayi. Prevalensi tertinggi di dapatkan pada bayi berusia 9-12 bulan. Kejadian tersebut terjadi mulai dari 7,1\% sampai $61 \%$ sedangkan kejadia diapers rash terjadi sekitar $25 \%$ pada bayi di Inggris. Sebanyak 54\% bayi berumur 1 bulan yang mengalami diaper rash setelah memakai popok(5). Penelitian lain juga mendapatkan hal yang sama bahwa kejadian diaper rash terjadi sekitar $15 \%$ sampai $50 \%$ (8).

Dari 17 responden yang memakai diaper didapatkan 15 bayi mengalami diaper rash karena sering menggunakan diaper. Hanya 2 responden yang tidak mengalami diaper rash. Dari hasil uji statistic didapatkan nilai $p$ value $0,004<\dot{\alpha} 0,05$ yang berarti terdapat hubungan pemakaian diaper dengan kejadian diaper rash pada bayi usia 6 bulan -1 tahun. Penggunaan 
diaper yang terlalu sering dapat menyebabkan diaper rash karena dapat menimbulkan berkembangbiakan mikro organism semakin banyak (5).

Diaper rash merupakan salah satu masalah kulit pada bayi dan anak, kurang lebih $50 \%$ bayi dan anak yang memakai popok pernah mengalaminya. Hasil penelitian terdahulu didapatkan bahwa 55,2\% menggunakan diaper dalam waktu yang lama dan mengalami diaper rash $69,0 \%$ dalam kategori berat. Hasil penelitian didapatkan keterkaitan antara penggunaan diaper dengan kejadian diaper rash dengan nilai t hitung 0,819> dari t tabel $0,491(20)$.

Terdapat 15 responden dari 17 responden mengalami diaper rash karena sering menggunakan diaper, dan hanya 2 responden yang tidak mengalami diaper rash. Hal tersebut bisa disebabkan karena kulit bayi tersebut tidak terlalu sensitif sehingga meskipun menggunakan diaper tidak menagalami gangguan dan karena diaper yang digunakan memiliki tipe yang baik atau lebih lembut (5).

Diaper rash dapat mengakibatkan gangguan pada pelindung kulit bayi. Penggunaan diaper yang lama dapat menyebabkan diaper rash yang menggagu kesehatan dari kulit bayi. Selain kurang terjaganya kebersihan dari bayi dari lingkungan juga karena kurangnya pengetahuan orang tua mengenai diaper rash. Disamping itu juga dapat mengganggu pertumbuhan dan perkembangan bayi karena hal tersebut bayi dapat mengalami gangguan untuk susah tidur dan rewel (17).

Seseorang perlu memiliki informasi tentang frekuensi, tingkat keparahan, jumlah kulit yang terlibat, dan durasi diaper rash untuk memahami dampak dari diaper rash pada potensi peningkatan penetrasi kulit dari zat yang bersentuhan dengan kulit. Perkembangan diaper rash sangat dipengaruhi oleh kebiasaan dan praktik pengasuh sehingga prevalensinya sangat bervariasi di berbagai wilayah di dunia. Ada beberapa perkembangan yang mengikuti perkembangan dan resolusi insiden diaper rash dari waktu ke waktu, sehingga informasi statistik tentang diaper rash biasanya hanya memberikan informasi tentang dalam waktu tertentu (3).

Lama Pemakaian diaper digunakan maksimal tiga jam sesuai dengan dengan waktu pada saat bayi minum. Diaper hendaknya diganti sekitar 3 jam sekali, agar kulit bayi tidak terlalu lama bersentuhan dengan asam laktat yang dapat menyebabkan gangguan pada kulit bayi. Disarankan agar sering mengganti diaper sehingga akan membuat bayi terasa nyaman dan terhindar dari terjadinya diapers rash. Selain hal tersebut orang tua juga bisa memilih diaper yang memiliki bahan yang lebut yang baik untuk kulit bayi.

Pada penelitian ini masih banyak responden yang tidak efektif dalam lama pemakaian diaper sehingga hampir setengahnya masih mengalami diaper rash yang mungkin sebelumnya ibu tidak tahu informasi tentang lama pemakaian diaper yang sesuai dan gangguan-gangguan lain pada saat memakai diaper. Responden yang tidak mengalami diaper rash dikarenakan ibu sudah mendapatkan informasi dari orang terdekat bisa dari saudara, teman, atau bahkan dari tenaga kesehatan. Orang tua diharapkan sudah mengajari anaknya toilet training sejak dini yaitu mulai usia 1,5 tahun, untuk mengurangi terjadinya diaper rash. Apabila anak belum memungkinkan untuk dilakukan toilet training maka bisa dilakukan dengan mengurangi penggunaan diaper dan sering mengganti diaper sesuai waktu yang sudah dijelaskan diatas.

\section{SIMPULAN}

Lama pemakaian diaper di Posyandu Desa Canggu Kecamatan Badas Kabupaten Kediri didapatkan bahwa responden menggunakan lama pemakaian diaper secara tidak efektif lebih dari 3 jam sebanyak 24 responden $(51,1 \%)$. Diaper rash yang dialami yaitu diaper rash ringan dan sedang masing-masing sebanyak 16 responden $(68,0 \%)$. Terdapat hubungan lama 
pemakaian diaper dengan kejadian diaper rash pada bayi usia 9-12 bulan di Posyandu Desa Canggu Kecamatan Badas Kabupaten Kediri Tahun 2018 dengan p-value sebesar 0,023 $(<0,05)$ dengan keeratan hubunganya yaitu 0,512 .

\section{SARAN}

Bagi Responden hendaknya mulai mengajari anak toilet training sejak dini pada saat anak mulai mengerti tentang penjelasan yang kita berikan atau saat anak berusia 1,5 - 2 tahun sehingga dapat mengurangi pemakaian diaper. Peneliti selanjutnya dapat mengembangkan penelitian tentang hubungan lama pemakaian diaper dengan kejadian diaper rash pada bayi usia 9-12 bulan, menggunakan metode penelitian yang berbeda serta penambahan variabel penelitian lain dan menambah jumlah responden untuk diteliti lebih lanjut. Penggunaan popok hendaknya menggunkan ukuran yang sesuai dengan tubuh atau berat badan bayi, dan jangan menggunakan popok yang terlalu ketat terutama pada saat mengalami diaper rash. Usahakan menggunakan jenis popok yang lembut untuk menghindari gesekan yang kasar dengan popok bayi.

\section{UCAPAN TERIMA KASIH}

Kami sampaikan terima kasih kepada masyarakat Desa Canggu Kecamatan Badas Kabupaten Kediri yang telah membantu dalam penelitian ini, serta kepada bidan Desa Canggu yang telah membatu dalam kelancaran penelitian ini. Penelitian ini didanai oleh Prodi D IV Bidan Pendidik STIKES Karya Husada Kediri tahun anggaran 2018 dan kami berterimakasih kepada Prodi DIV Bidan Pendidik atas dukungan dan kepercayaan untuk mengembangkan tri dharma dalam perguruan tinggi dalam bidang penelitian.

\section{DAFTAR PUSTAKA}

1. Maryuni A. Ilmu kesehatan anak dalam kebidanan. Jakarta: CV. Trans info media. 2010. 207-223 p.

2. Odio M, Thaman L. Diapering, diaper technology, and diaper area skin health. Pediatr Dermatol. 2014;31:9-14.

3. Felter SP, Carr AN, Zhu T, Kirsch T, Niu G. Safety evaluation for ingredients used in baby care products: Consideration of diaper rash. Regul Toxicol Pharmacol. 2017;90:214-21.

4. Neal-Kluever A, Aungst J, Gu Y, Hatwell K, Muldoon-Jacobs K, Liem A, et al. Infant toxicology: state of the science and considerations in evaluation of safety. Food Chem Toxicol. 2014;70:68-83.

5. Aisyah S. Hubungan pemakaian diapers dengan kejadian ruam popok pada bayi usia 612 bulan. J Midpro. 2018;8(1):8.

6. Sujatni RA, Hartini S, Kusuma MAB. Pengaruh Lamanya Pemakaian Diapers Terhadap Ruam Diapers Pada Anak Diare Usia 6-12 Bulan Di Rsud Tugurejo Semarang. Karya Ilm. 2013;

7. Kristiyanasari W. Asuhan Keperawatan Neonatus dan Anak. Jakarta Med B. 2011;

8. Adalat S, Wall D, Goodyear H. Diaper dermatitis-frequency and contributory factors in hospital attending children. Pediatr Dermatol. 2007;24(5):483-8.

9. Saadatmand M, Stone KJ, Vega VN, Felter S, Ventura S, Kasting G, et al. Skin hydration analysis by experiment and computer simulations and its implications for diapered skin. Ski Res Technol. 2017;23(4):500-13.

10. Fluhr JW; Darlenski R; Lachmann N; Baudouin C; Msika P; De Belilovsky; Chachem. Infant epidermal skin physiology: adaptation after birth. $\mathrm{Br} \mathrm{J}$ Dermatol. 2012;166(3):483-90. 
11. Klunk C, Domingues E, Wiss K. An update on diaper dermatitis. Clin Dermatol. 2014;32(4):477-87.

12. Visscher MO, Adam R, Brink S, Odio M. Newborn infant skin: physiology, development, and care. Clin Dermatol. 2015;33(3):271-80.

13. Ersoy-Evans S, Akıncı H, Doğan S, Atakan N. Diaper dermatitis: a review of 63 children. Pediatr Dermatol. 2016;33(3):332-6.

14. Safety SC on C. Basic criteria for the in vitro assessment of dermal absorption of cosmetic ingredients. Eur Comm. 2010;1-14.

15. Kosim MS, Yunanto A, Dewi R, Sarosa GI, Usman A. Buku Ajar Neonatologi Edisi Pertama. Jakarta BadanPenerbit IDAI. 2014;

16. Fitria EI. Asuhan Kebidanan Neonatus Bayi, Balita dan Anak Prasekolah. Jakarta Timur: CV. Trans Info Media. 2015;

17. Kusumastuti MJ; Alfiyanti D. Peningkatan Pengetahuan Ibu Tentang Diaper Dermatitis Dengan Program Penyuluhan Kesehatan Di Posyandu Melati Desa Brumbung. Karya Ilm. 2017;6(1).

18. Stamatas GN, Tierney NK. Diaper dermatitis: etiology, manifestations, prevention, and management. Pediatr Dermatol. 2014;31(1):1-7.

19. Aurora DD, Lestari Y, Meryandini A. Identifikasi bakteri penghasil mananase serta karakterisasi enzimnya. J Mikrobiol Indon. 2003;8(1):31-3.

20. Naimah A. Hubungan Pemakaian Popok Sekali Pakai Pada Balita (Usia 0-3 Tahun) Dengan Terjadinya Dermatitis Alergi Popok Di Purwoharjo Banyuwangi. Indones J Heal Sci. 2019;11(2):167-76. 